\title{
M7 subtype leukemic cell edge detection techniques with threshold value comparison and noise filters
}

\author{
A.S.A.Salam ${ }^{1}$, M.N.M.Isa ${ }^{2}$, M.I.Ahmad ${ }^{3}$ \\ ${ }^{1,2}$ School of Microelectronic Engineering, Universiti Malaysia Perlis, Pauh Putra Campus, Malaysia \\ ${ }^{3}$ School of Computer and Communication Engineering, Universiti Malaysia Perlis, Malaysia
}

\begin{tabular}{l} 
Article Info \\
\hline Article history: \\
Received Oct 10, 2018 \\
Revised Dec 7, 2018 \\
Accepted Dec 18, 2018 \\
\hline
\end{tabular}

Keywords:

AML

Edge detection

Leukemia cell

M7

Noise filters

\begin{abstract}
The aim of this paper is to study and identify various threshold values for two prevalently used edge detection techniques, which are Sobel and Canny. The purpose is to determine which value gives an accurate result for identifying a leukemic cell. Moreover, evaluating suitability of edge detectors is also essential as feature extraction of cell depends greatly on image segmentation (edge detection). Firstly, an image of M7 subtype of Acute Myelocytic Leukemia (AML) is selected due to its diagnosing which were found lacking. Next, apply noise filters for the best of image quality. Thus by comparing image with no filter, median and average filters, useful information can be acquired. Each edge detectors is fixed with threshold value of 0-0.5 but for Cann edge detection the value can increase until 0.9. From the research, it is found that Canny edge with no filter and a threshold value of 0.7 gives a clearer image with less noise reduction.
\end{abstract}

Copyright @ 2019 Institute of Advanced Engineering and Science. All rights reserved.

\section{Corresponding Author:}

Mohd Nazrin bin Md Isa,

School of Microelectronic Engineering,

Universiti Malaysia Perlis,

Pauh Putra Campus, 02600, Arau, Perlis, Malaysia.

Email: nazrin@unimap.edu.my

\section{INTRODUCTION}

Leukemia cells in humans are growing rapidly each year. In 2016, statistics shows that 24,400 people are expected to die from this disease [1] Leukemia is one of the deathly diseases amongst humans and it is also known as a bone marrow disorder. This disease involves abnormalities of white blood cells proliferation that disables the cells to function normally [2].The disease is grouped by how quickly the illness develops. It can either be acute or chronic [3]. Also, Leukemias are grouped by affected blood cell type (lymphocytes or myelocytes). This disease is categorized into four main types which includes acute lymphocytic leukemia (ALL), chronic lymphocytic leukemia (CLL), acute myelocytic leukemia (AML) and chronic myelocytic leukemia (CML) [4]. Each leukemia type has its particular properties or shape to differentiate one another. Acute Leukemia grows briskly which can invade the body within a few weeks or months. Chronic Leukemia on the other hand, takes time growing but progressively worsens over the years.

Acute Myelogenous Leukemia is a heterogenous group of clonal disorders, which usually not detected until it has spread into other organs. AML is classified by a system known as French-American British (FAB) classification which categorized into eight subtypes M0 until M7[5]. Table 1 shows the subtypes of $A M L$ classification. Each subtypes varies in properties like the size and number of leukemia cells. The usage of edge detection becomes a major part in detecting these changes of cell shape. M7 subtypes have been distinguished over the years by the uses of cytochemical and morphological criteria which were found lacking [6]. Moreover it has been found that 3-10\% of primary childhood $A M L$ and children may consists of varieties of symptoms such as low-grade fever, diarrhea and easy bruising[7]. Studies have been conducted that this type of leukemia is usually abnormally abundant in children with Down Syndrome cases. 
Table 1. French-American-British Classification [6]

\begin{tabular}{cl}
\hline FAB Subtypes & \multicolumn{1}{c}{ Name } \\
\hline M0 & Undifferentiated acute myeloblastic leukemia \\
M1 & Acute myeloblastic leukemia with minimal maturation \\
M2 & Acute myeloblastic leukemia with maturation \\
M3 & Acute promyelocytic leukemia (APL) \\
M4 & Acute myelomonocytic leukemia \\
M4 eos & Acute myelomonocytic leukemia with eosinophilia \\
M5 & Acute monocytic leukemia \\
M6 & Acute erythroid leukemia \\
M7 & Acute megakaryoblastic leukemia \\
\hline
\end{tabular}

Image segmentation is one of the crucial steps in an automatic leukocyte recognition system[8]. This is because the last two steps after segmentation depends greatly on the result of segmentation. Edge detection is part of image segmentation. Edge detection contains significant information. It reduces the image size and filters out information that are less convenient [9]. Edges typically occur on the boundary between two different region in an image [10].Frequently, this detection is the first step in recovering information from images. Detecting edges greatly rely on the noise, intensity, brightness and blur. Thus, by working with different edges of the same image, differences can be observe and the selected suitable algorithm will be chosen to further the next stage of image processing (feature extraction). Edge detection can come with a threshold value which functions to detect edges. Typically the lower the threshold value, more edges can be detected [11]. However, it is not necessarily the many edges found can make an image looks great. Due to it's advantages, edge detection continues to be an active research area.

Author [10] had conducted a research study in identifying prawn species using various edge detection which are Sobel, Canny, Prewitt and Robert. It had been shown that Canny yielded the best result as it is able to detect maximum number of edges and edges at the corner. Author also suggested that by using Canny, the algorithms can be modified by adjusting the parameters which are able to adapt in numerous environment.

Khairudin and Irmawati [12] performed analysis in edge detection comparison for USG images for fetal development in the womb. The techniques involved Sobel, Canny and Prewitt. These 3 detectors are analysed with mean Square Error (MSE) and Peak Signal to Noise Ratio (PSNR). Result shows that Sobel gives perfect outcome compared to others due to its smooth morphology and all the lines are connected in details.

Other than that [13] studied automated screening system for Acute Myelogenous Leukemia using Sobel operator as its edge enhancement. Sobel ables to enhance the borders of the membranes and the cells which helps to segment grouped cells and subsequent edge detection. Other than that author also performs Canny edge detection that functions to obtain outputs with continuous edges. This is also agreed with [14].

A review of AML conducted by [15] uses Canny edge detector for extraction of nucleus. This edge detector follows by [16] which uses Canny for searching nucleus boundary and also cytoplasm for segmentation in cervical cancer detection. The author uses sensitivity of 0.634 .

Threshold based edge detection studied by [17] conducts variety of edge detectors which includes Sobel, Prewitt, Robert, Canny, LoG, Expectation-Maximization (EM) algorithm, OSTU and Genetic Algorithm. The study also compares different noise filters and harmonic filter gives out the best image output. A threshold range of 0.62-0.8 is also compared and a threshold value of 0.68 yields the best result.

Hence, this paper will be about the study of different edge detection techniques (Sobel and Canny) which then will be compared with one another to select which is the best techniques to be applied on detecting edges on an M7 subtype leukemic cell. The system should able to recognize the cell pattern and shape. A threshold value of 0 until 0.8 is chosen. The threshold value will determine how many edges are available to be detected in an image. Filters (median and averaging) which is for noise removal will also be studied to find which is the most suitable filter to minimise/remove noise filters.

\section{RESEARCH METHOD}

Figure 1 shows a flowchart of the overall proposed methodology for this study. This section will explain briefly the procedure from image acquisition to the newly image obtained. 


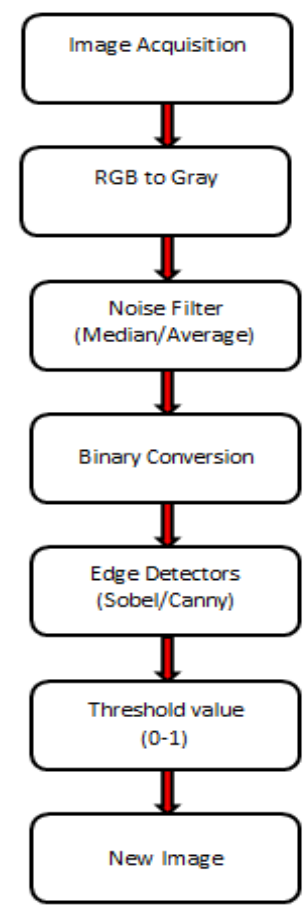

Figure 1. Proposed methodology flowchart.

The image on Figure 2 is one of the types of M7 image that was acquired from clinical flow. The microscopic image consists of 6 blast cells (purple region) that are megakaryocyte. It is blast and M7 due to the dispersed and eccentric nucleus [18]. In addition, the cytoplasm appears to be non-granular, basophilic and similar appearance to platelets. Moreover, fragments of megakarioblasts seen in peripheral blood.

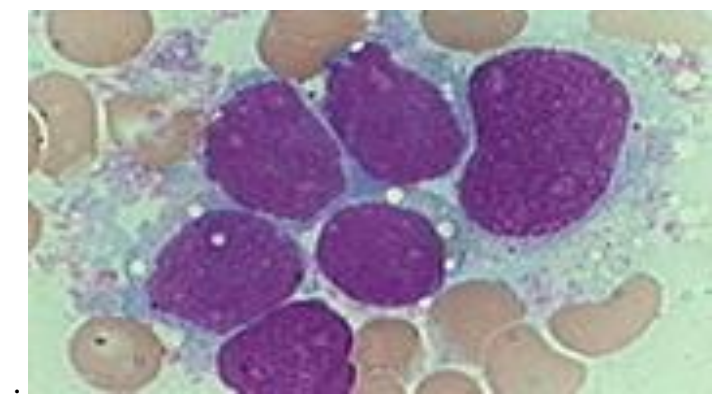

Figure 2. M7 subtype of $A M L$ cell

The RGB image obtained from Figure 2 is converted into gray scale (Figure 3 ) to reduce dimension of image [19]. Moreover, processing becomes flexible when a single intensity value of each pixel is specified [20].

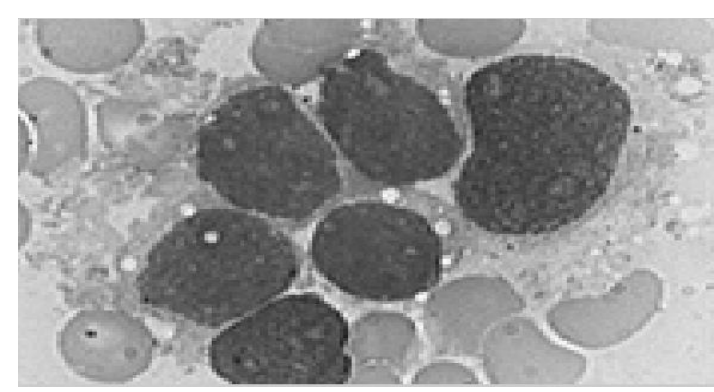

Figure 3. Gray scale image 
Filtering is removing some frequencies in order to suppress interfering signals and reduce background noise [18]. In other words, Filtering is a device or process that removes signal of unwanted component or feature. Filters can come in High Pass or Low pass depending on the amount of noise needs to be filter. This paper is about removing noise using Low pass filter of averaging filter and median filter.

Average filter or mean filter functions to smooth the image into non-noise image [21]. The smoothing filters are used for image blurring and noise reduction in spatial domain.

Median filter is a nonlinear image processing operation used to remove the impulsive noise from images [22]. They are most preferred against impulsive noise due to their robustness and denoising power.

For more accurate analysis, the gray scale image is converted to black and white (Binary) [20] as shown in Figure 4. The matlab function used is the imb2w function.

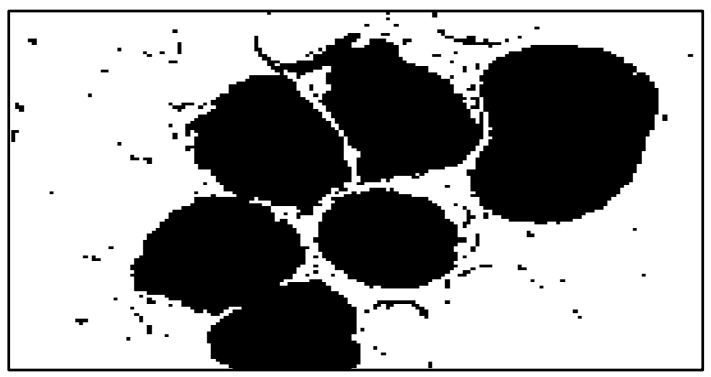

Figure 4. Binary conversion

The Function of Sobel edge detector is for detecting vertical and Horizontal edges in an image known as $\mathrm{Gx}$ and $\mathrm{Gy}[23]$. It also combines information into a single matrix. The operator consists of 3x3 convolution kernels by which one kernel is simply rotated by $90^{\circ}$ by the other as shown in Figure 5 [10].

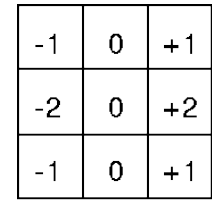

Gx

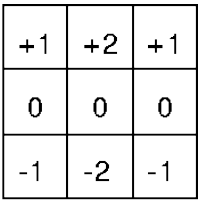

Gy

Figure 5. Sobel masks

The kernels can be joined together to find the absolute magnitude and the orientation of the gradient as shown in (1).

$$
|\mathrm{G}|=\sqrt{G x^{2}+G y^{2}}
$$

where : $|\mathbf{G}|=$ Gradient magnitude

$G x=$ Horizontal convolution mask

$G y=$ Vertical convolution mask

Canny edge detection is also known as the optimal edge detector [24] which satisfies all of the performance criteria. Canny comes in several steps as follow [10-11] [23-25]:

1) Gaussian filtering for noise removal

$$
\mathrm{G} \sigma=\frac{1}{\sqrt{2 \pi \sigma^{2}}} e^{\left[-\frac{m^{2}+n^{2}}{2 \sigma^{2}}\right]}
$$

Where : $G \sigma=$ Gaussian filtering

2) Finding the intensity and gradient of image whereby it uses four filters to find out the vertical, horizontal and diagonal edges to find the blurred image. 
$M(m, n)=\sqrt{g^{2} m(m, n)+g^{2} n(m, n)}$

and,

$$
\theta=\tan ^{-1}\left[\frac{g n(m, n)}{g m(m, n)}\right]
$$

3) Non maximum suppression for thinning of the edge

4) Double threshold to get rid of spurious responses from bothering factors such as noise and colour variation.

5) Track edge by hysteresis to achieve accurate result by getting rid of weak edges caused by latter reasons.

The aim of threshold is to determine which pixels fall into each category [26]. A straightforward thresholding method uses a single value of intensity and relying on it, every pixel can belong to one of two categories:

a. Low intensity of pixel $=$ pixel set to black

b. High intensity of pixel $=$ pixel set to white

In Matlab, BW = edge(I,'edge',thresh) is one of the easiest method to detect edge by using threshold. The thresh specifies the sensitivity threshold for the particular edge method[18].If the thresh is not specify or empty, edge chooses the value automatically. In this paper a threshold value of $0-1$ is used to compare which value gives out the best effect of M7 subtypes of $A M L$.

Newly edge detection image are shown in the next section whereby Sobel and Canny compared with the two median filters, mean and average. In addition, the two detectors also compared when there is no filter.

\section{RESULTS AND ANALYSIS}

In this section, The results from both edge detection, noise filters and threshold value are compared with one another and further analysis are done in selecting which threshold values are apt for M7 subtypes $A M L$.

\subsection{Sobel}

For more accurate analysis sobel as shown in Figure 6, 7 and 8.

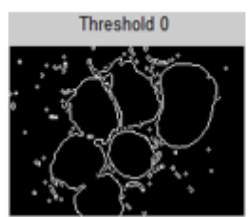

(a)

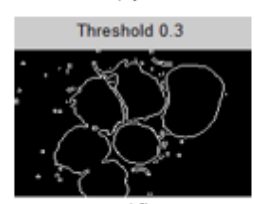

(d)

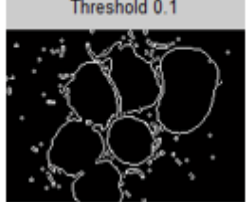

(b)

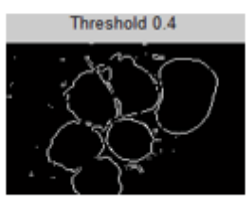

(e)

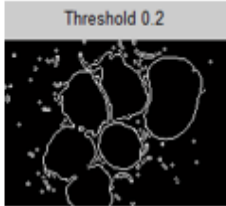

(c)

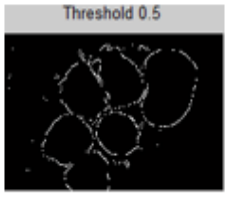

Figure 6. (a) Without filter $0(b)$ Without filter $0.1(c)$ Without filter $0.2(d)$ Without filter 0.3 (e) Without filter $0.4(f)$ Without filter 0.5

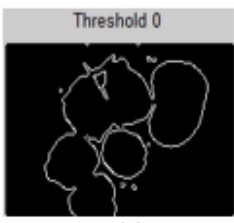

(a)

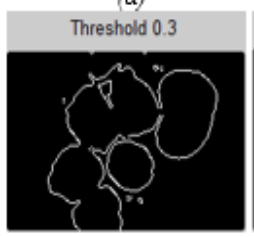

(d)

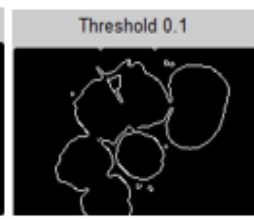

(b)

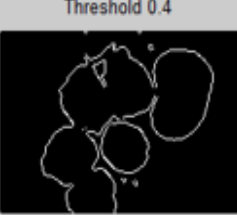

(e)

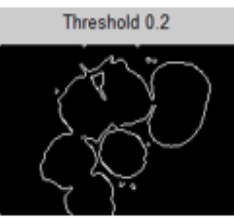

(c)

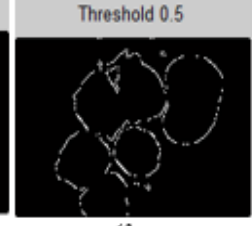

(f)
Figure 7. (a) Median filter 0 (b) Median filter 0.1

(c) Median filter $0.2(d)$ Median 0.3

(e) Median filter $0.4(f)$ Median filter 0.5 


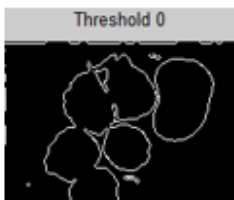

(a)

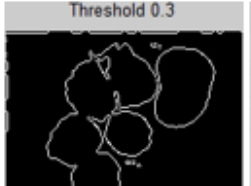

(d)

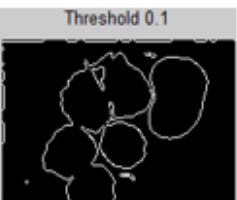

(b)

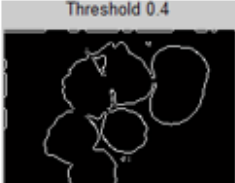

(e)

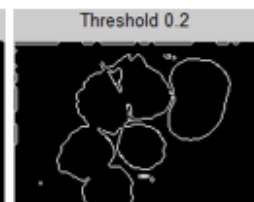

(c)

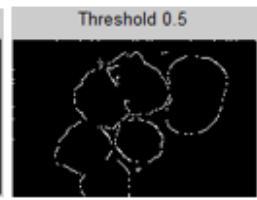

$(f)$

Figure 8. (a) Averaging filter $0(b)$ Averaging filter 0.1 (c) Averaging filter 0.2, (d) Averaging 0.3 (e) Averaging filter $0.4(f)$ Averaging filter 0.5

\subsection{Canny}

Analysis canny as shown in Figure 9, 10 and 11.
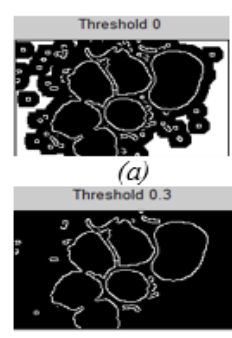

(d)

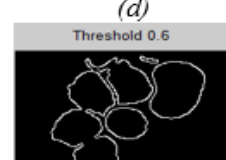

(g)

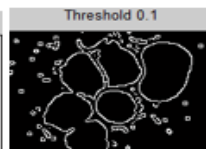

(b)

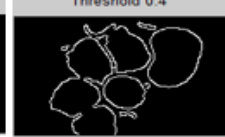

(e)

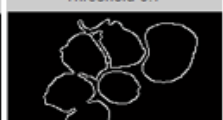

(h)

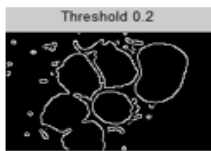

(c)
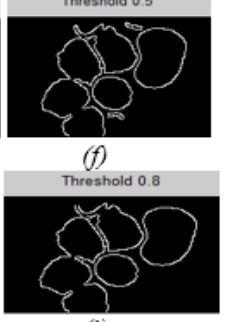

(i)

Figure 9. (a) Without filter 0 (b) Without filter 0.1 (c) Without filter $0.2(d)$ Without filter 0.3

(e) Without filter $0.4(f)$ Without filter 0.5

$(g)$ Without filter $0.6(h)$ Without filter 0.7 (i) Without filter 0.8

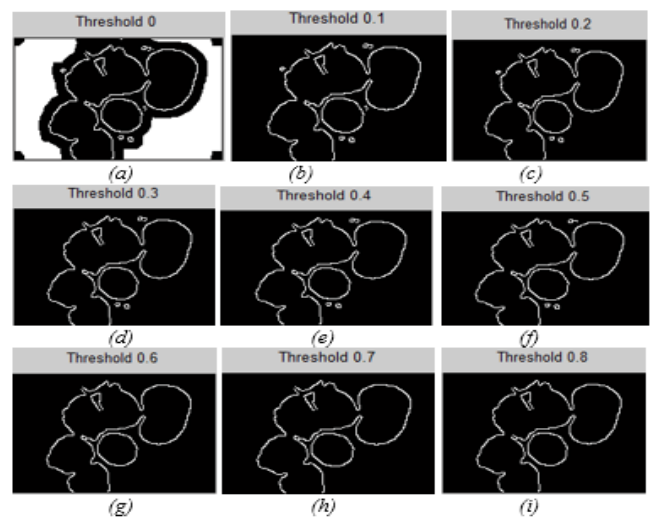

Figure 10. (a) Median filter 0 (b) Median filter 0.1

(c) Median filter $0.2(d)$ Median filter 0.3

(e) Median filter $0.4(f)$ Median filter 0.5

$(g)$ Median filter $0.6(h)$ Median filter 0.7

(i) Median filter 0.8

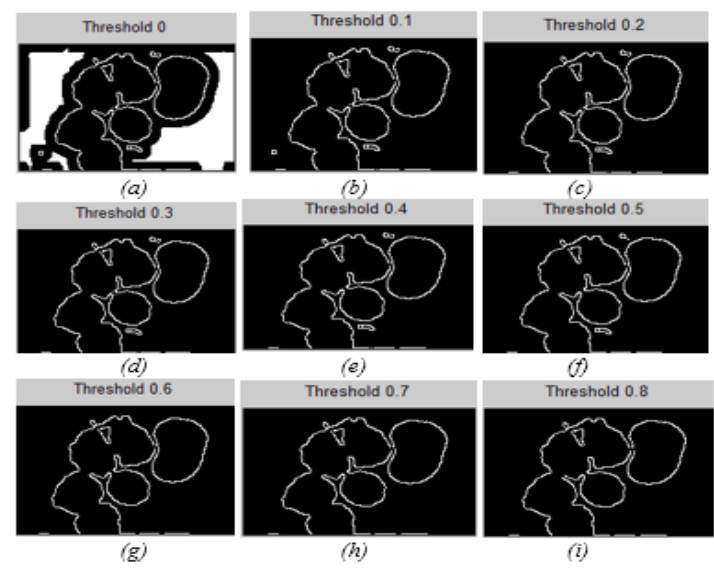

Figure 11. (a) Averaging filter $0(b)$ Averaging filter $0.1(c)$ Averaging filter $0.2(d)$ Averaging $0.3(e)$ Averaging filter $0.4(f)$ Averaging filter $0.5(g)$ Averaging filter $0.6(h)$ Averaging filter $0.7(i)$ Averaging filter 0.8 


\subsection{Tabulated Results}

Table 2 and Table 3 show the overall analysis of this paper. Leukocyte are identified by its shape. It represents a regular shape and a compact nucleus with regular and continuous edges. In terms of image processing, the nuclei appear darker than the background [27]. This is how blast cells are identified thus by applying different threshold, it is easier to pick out which values gives the best effect on the M7 subtypes of AML.

The result of Sobel edge detection proves that noise will decrease as threshold increase. However, the edge lines will gradually disappear as threshold increase. Based on the analysis, for non-filtering cases of Canny using threshold 0.7 ; the cell appears much clearer with only a few noises left and two cells overlap but are able to identify that they are different because the overlapping case does not make much differences. Overall, with average filter when there is no threshold, the image will produce a border but gradually fades as threshold increase. Other than that, Sobel edge's line fades as threshold increase but for Canny, the edge still maintains with an increase sharpness of line. This is due to Canny edge detection having to do double threshold and finding intensity and gradient of image.

Sobel edge threshold can only be apply up to 0.5 . Values greater than that will produce a black background. For Canny, it can go up to 0.9 but as threshold gets to 0.8 it will gradually fades.

Table 2. Overall Results for Sobel

\begin{tabular}{|c|c|c|c|}
\hline \multirow{2}{*}{ Th } & \multicolumn{3}{|c|}{ Filter } \\
\hline & No Filter & Median & Averaging \\
\hline 0.0 & $\begin{array}{l}\text {-background noise } \\
\text { - Two cells overlap }\end{array}$ & $\begin{array}{l}\text { - Overlap cells } \\
\text { - Hardly background } \\
\text { noise }\end{array}$ & $\begin{array}{l}\text { - Hardly background } \\
\text { noise } \\
\text { - Border shown } \\
\text { - Overlapping cells }\end{array}$ \\
\hline 0.1 & - Similar to 0.0 & Similar to 0.0 & Similar to 0.0 \\
\hline 0.2 & $\begin{array}{l}\text { - Not much different } \\
\text { with } 0.0 \text { and } 0.1\end{array}$ & $\begin{array}{l}\text { - Not much different } \\
\text { with } 0.0 \text { and } 0.1\end{array}$ & $\begin{array}{l}\text { - Not much different } \\
\text { with } 0.0 \text { and } 0.1\end{array}$ \\
\hline 0.3 & $\begin{array}{l}\text { Background noise } \\
\text { gradually fades }\end{array}$ & - Decrease of noise & - Noise lessens \\
\hline 0.4 & $\begin{array}{l}\text { - Less background noise } \\
\text {-Blast edges are starting } \\
\text { to fade }\end{array}$ & $\begin{array}{l}\text { - Less noise compare to } \\
\text { Th } 0.3\end{array}$ & - Bits of noises are gone \\
\hline 0.5 & $\begin{array}{l}\text { - Blast edges gradually } \\
\text { diminishes } \\
\text {-Background noise } \\
\text { reduces exponentially }\end{array}$ & $\begin{array}{l}\text { - Blast edges fades } \\
\text { gradually } \\
\text {-Cells still overlap }\end{array}$ & $\begin{array}{l}\text { - Background fades } \\
\text {-Blast edges diminishes }\end{array}$ \\
\hline
\end{tabular}

Table 3. Overall Results for Canny

\begin{tabular}{|c|c|c|c|}
\hline \multirow{2}{*}{ Th } & \multicolumn{3}{|c|}{ Filter } \\
\hline & No Filter & Median & Averaging \\
\hline 0.0 & $\begin{array}{l}\text { - Background noise } \\
\text {-Mixed black and white } \\
\text { background }\end{array}$ & $\begin{array}{l}\text { - Five overlap cells } \\
\text { Mixed black and white } \\
\text { background }\end{array}$ & $\begin{array}{l}\text {-Four overlap cells } \\
\text { - Mixed black and white } \\
\text { background } \\
\text {-Black border }\end{array}$ \\
\hline 0.1 & -Fully black background & -Fully black background & $\begin{array}{l}\text {-Fully black background } \\
\text { - Parts of background are } \\
\text { still left }\end{array}$ \\
\hline 0.2 & $\begin{array}{l}\text { - Noise reduces } \\
\text { exponentially }\end{array}$ & $\begin{array}{l}\text {-Noise count is lesser } \\
\text { compare to } 0.1\end{array}$ & $\begin{array}{l}\text {-Noise count is lesser } \\
\text { compare to } 0.1\end{array}$ \\
\hline 0.3 & $\begin{array}{l}\text {-Background noise } \\
\text { gradually fades }\end{array}$ & $\begin{array}{l}\text {-Noise count is lesser } \\
\text { compare to } 0.2\end{array}$ & $\begin{array}{l}\text {-Noise count is lesser } \\
\text { compare to } 0.2\end{array}$ \\
\hline 0.4 & $\begin{array}{l}\text {-Noise count is lesser } \\
\text { compare to } 0.3\end{array}$ & -Similar with Th 0.3 & -Similar with Th 0.3 \\
\hline 0.5 & $\begin{array}{l}\text {-Noise count is lesser } \\
\text { compare to } 0.4\end{array}$ & -Noise reduce & -Noise Reduce \\
\hline 0.6 & $\begin{array}{l}\text { - Noise almost gone } \\
\text { completely } \\
\text { - Two cells overlap }\end{array}$ & $\begin{array}{l}\text { - Salt and pepper noise are } \\
\text { gone }\end{array}$ & $\begin{array}{l}\text {-Salt and pepper noise are } \\
\text { gone } \\
\text { - There are still dotted } \\
\text { background left }\end{array}$ \\
\hline 0.7 & $\begin{array}{l}\text {-Salt and pepper noise are } \\
\text { gone } \\
\text { - Two cells overlap }\end{array}$ & - Similar result with Th 0.6 & - Similar result with Th 0.6 \\
\hline 0.8 & $\begin{array}{l}\text { - Blast edges gradually } \\
\text { fades }\end{array}$ & $\begin{array}{l}\text {-Similar result with Th } 0.7 \\
\text {-Edges gradually fades }\end{array}$ & $\begin{array}{l}\text {-Similar result with Th } 0.7 \\
\text {-Edges gradually fades }\end{array}$ \\
\hline
\end{tabular}




\section{CONCLUSION}

Concisely, this paper is about finding suitable edge detection techniques (Sobel and Canny) for M7 subtype $A M L$ to further on the next step of image processing after segmentation step, which is feature extraction. The image tests with different threshold values (0.0-0.8) and filters (averaging filter and median filter) to give out the best result. It seems that with no filter and a threshold of 0.7, canny edge detection is suitable to be picked since noise decreases greatly compare to Sobel. This result agrees with [16] and [17] as the best threshold picked for their image is 0.634 and 0.68 respectively, which is closer to 0.7. Also aforementioned with its ability to give better detection in terms of noise detection, Canny also filters noise earlier in one of it steps hence it does not require additional filter to remove the noise. Albeit that there are still one or two background noises left, Canny managed to produce a clearer edge line compare to Sobel. For future reference it is good to try on different low pass filter so that the background noise will completely be removed and solve the problem of overlapping cell cases.

\section{REFERENCES}

[1] L. R. A., "Facts and Statistics," LaRussaA, 03- Mar-2015.[Online]. Available: https://www.lls.org/http\%3A/llsorg.pro d.acquia-sites.com/facts-and-statistics/facts-and-statistics-overview/factsand-statistics. [Accessed: 14-Mar-2017].

[2] S. Mohapatra, D. Patra, and S. Satpathy, "An ensemble classifier system for early diagnosis of acute lymphoblastic leukemia in blood microscopic images," Neural Comput. Appl., vol. 24, no. 7-8, pp. 1887-1904, 2014.

[3] M. D. M. C. Stöppler, "Leukemia: Symptoms, Survival Rate, andDiagnosis,"MedicineNet.[Online]. Available: http://www.medicinenet.com/leukemia/article.htm. [Accessed: 14-Mar- 2017].D. Zhang, et al., "Common Mode Circulating Current Control of Interleaved Three-Phase Two-Level Voltage-Source Converters with Discontinuous Space-Vector Modulation," 2009 IEEE Energy Conversion Congress and Exposition, Vols 1-6, pp. 39063912, 2009.

[4] A.Boyle,"Types Of Leukemia," EmpowHER, 28- Oct- 2014. [Online]. Available: http://www.empowher.com/leukemias/content/types-leukemia. [Accessed: 14-Mar-2017].

[5] "How Is Acute Myeloid Leukemia Classified?," American Cancer Society. [Online]. Available: https://www.cancer.org/cancer/acute-myeloileukemia/detection-diagnosis-staging/howclassified.html [Accessed:15- Mar-2017].

[6] A. Carroll et al., "The $\mathrm{t}(1 ; 22)(\mathrm{p} 13 ; \mathrm{q} 13)$ is nonrandom and restricted to infants with acute megakaryoblastic leukemia.

[7] P. D. Mueller and W. S. Korey, "A case report: Acute myeloid leukaemia," IranJ.Paediatr.Haematol. Oncol., vol, no. 4, pp. 7-10, 1998

[8] G.Gu and D.Cui, "Polar angle detection and image combination based leukocyte segmentation for overlapping cell images," Comput. Informatics, vol. 30, no. 1, pp. 189-199, 2011.

[9] Y. Zheng, J. Rao, and L. Wu, "Edge detection methods in digital image processing," Comput. Sci. Educ. (ICCSE), 2010 5th Int. Conf., pp. 471-473, 2010.

[10] V. Sucharita, S. Jyothi, and D. M. Mamatha, "A Comparative Study on Various Edge Detection Techniques used for the Identification of Penaeid Prawn Species," vol. 78, no. 6, pp. 1-5, 2013.

[11] G. T. Shrivakshan and C. Chandrasekar,"A Comparison of various Edge Detection Techniques used in Image Processing," Int. J. Comput. Sci. Issues, vol. 9, no. 5, pp. 269-276, 2012.

[12] M. Khairudin, "Comparison Methods of Edge Detection for USG Images," pp. 85-88, 2016.

[13] S. Agaian, M. Madhukar, and A. T. Chronopoulos, "Automated screening system for acute myelogenous leukemia detection in blood microscopic images," IEEE Syst. J., vol. 8, no. 3, pp. 995-1004, 2014.

[14] F. Kazemi, T. A. Najafabadi, and B. N. Araabi, "Automatic Recognition of Acute Myelogenous Leukemia in Blood Microscopic Images Using K-means Clustering and Support Vector Machine," Journal of Medical Signals and Sensors, 2016.[Online].Available: https://www.ncbi.nlm.nih.gov/pmc/articles/PMC4973462/. [Accessed: 12-May-2017].

[15] H. Mahmood et al. " "A review of AML classification: A single institution experience in a developing country," J. Hematop., vol. 7, no. 1, pp. 3-8, 2014.

[16] A. H. Mbaga, "Pap Smear Images Classification for Early Detection of Cervical Cancer," vol. 118, no. 7, pp. 8887, 2015.

[17] B. Poornima, Y. Ramadevi, and T. Sridevi, "Threshold Based Edge Detection Algorithm," vol. 3, no. 4, pp. 400-403, 2011.

[18] W. Ladines-Castro et al., "Morphology of leukaemias," Rev.Médica Del Hosp. Gen. México, vol. 79, no. 2, pp. 107-113, 2015.

[19] H. Vaghela, H. Modi, M. Pandya, and M. Potdar, "Leukemia Detection using Digital Image Processing Techniques," Int. J. Appl. Inf. Syst., vol. 10, no. 1, pp. 43-51, 2015.

[20] K. Raghul, A. S. Raj, and P. U. Ilavarasi, “Acute Lymphocytic Leukemia Detection by Image Processing Using Matlab," vol. 24, pp. 263-267, 2016.

[21] C. M. Tsai and Z. M. Yeh, "Fast spatial averaging filter," Proc. - 2012 Int. Symp. Comput. Consum. Control.IS3C 2012, no. 1 pp. 153-156, 2012. 
[22] L. A. Aranda, P. Reviriego, and J. A. Maestro, "Error Detection Technique for a Median Filter," IEEE Trans. Nucl. Sci., vol. X, no. X, pp. 1-1, 2017.

[23] V. G. Narendra and K. S. Hareesh, "Study and comparison of various image edge detection techniques used in quality inspection and evaluation of agricultural and food products by computer vision," vol. 4, no. 2, 2011.

[24] K. Ogawa, Y. Ito, and K. Nakano, "Efficient Canny Edge Detection Using a GPU," 2010 First Int. Conf. Netw. Comput., pp. 279-280, 2010.

[25] T. Nadu and T. Nadu, "Automatic Tuberculosis Screening Using Canny Edge Detection Method," no. Icecs, pp. 282-285, 2015.

[26] P. Anghelescu, V. G. Iliescu, and A E.Detection, "Automatic Thresholding Method for Edge Detection Algorithms".

[27] L. Putzu and C. Di Ruberto, "White Blood Cells Identification and Classification from Leukemic Blood Image," Proc. IWBBIO Int. Work no. January, pp. 18-20, 2013.

\section{BIOGRAPHIES OF AUTHORS}

\begin{tabular}{|l|l|}
\hline & $\begin{array}{l}\text { Ms. Afifah Salmi Abdul Salam is a Master by Research student in Universiti Malaysia Perlis } \\
\text { under the School of Microelectronics. Her field of interest is Medical Image processing } \\
\text { specifically in Acute Myeloid Leukemia detection. She graduated from Universiti Malaysia } \\
\text { Terengganu, in } 2016 \text { with a Bachelor Degree of Applied Science (Physics, Electronic and } \\
\text { Instrumentation). }\end{array}$ \\
\hline & $\begin{array}{l}\text { Dr. Mohd Nazrin Md Isa is a senior lecturer in the School of Microelectronic Engineering at } \\
\text { Universiti Malaysia Perlis (UniMAP). Currently, he is a member of Integrated Circuits and } \\
\text { Systems Design (ICASe) group. His research interests include reconfigurable architectures, } \\
\text { bioinformatics and computational biology, field programmable gate array (FPGA) and ASIC } \\
\text { design. He graduated his doctorate study from the University of Edinburgh, Scotland, UK in } \\
\text { 2013. His PhD thesis entitled "High Performance Reconfigurable Architectures for Biological } \\
\text { Sequence Alignments" }\end{array}$ \\
\hline & $\begin{array}{l}\text { Dr Muhammad Imran Ahmad received his PhD in Computer Engineering from Newcastle } \\
\text { University, United Kingdom in 2014. Currently he is a senior lecturer at School of Computer and } \\
\text { Communication Engineering, Universiti Malaysia Perlis. His research interests include } \\
\text { biometric, signal analysis and image processing. }\end{array}$ \\
\hline &
\end{tabular}

